\title{
The long road to automated trucking: Insights from driver focus groups
}

\author{
Anirudh Kishore Bhoopalam*1, Roy van den Berg ${ }^{1}$, Niels Agatz ${ }^{1}$, and Caspar G \\ Chorus $^{2}$ \\ ${ }^{1}$ Rotterdam School of Management, Erasmus University \\ ${ }^{2}$ Faculty of Technology, Policy, and Management, TU Delft
}

\begin{abstract}
With the rapid progress of automated driving technology, self-driving vehicles are on the horizon. In this study, we look at what is likely to be the first implementation of a form of automated driving on public roads, i.e., truck platooning, where virtually connected trucks drive at short headways to save fuel and associated emissions. With progressing technology, we may see platoons with drivers resting while being in the truck or even platoons in which not all trucks require drivers. Hence, platooning technology has a significant impact on the jobs of truck drivers. Driver acceptance of this emerging technology is therefore an important factor in the implementation of platooning and, consequently, automated driving in general. In this study, we explore the range of perspectives that exist among drivers by conducting focus groups in the Netherlands. These discussions indicate that drivers foresee that platooning will eventually become a reality but believe it will have a negative impact on the quality of their work and their job satisfaction.
\end{abstract}

\section{Introduction}

Rapid developments in automotive technologies continue to advance the realization of autonomous vehicles. Several semi-autonomous features such as cruise control, parking assist, and lane-keeping assist have become commonplace (Yang and Coughlin, 2014) while companies like Tesla offer more advanced features like autopilot (Tesla, 2021). Tests with fully autonomous or self-driving vehicles are well underway. A recent overview by CB Insights (2020) reports the progress of over forty companies making inroads in this space.

\footnotetext{
${ }^{*}$ Corresponding author: kishorebhoopalam@rsm.nl
} 
Autonomous vehicle technology gives rise to several potential benefits. By eliminating human error and inconsistencies, it is likely that autonomous vehicles will elevate safety levels and improve traffic flow (Gruel and Stanford, 2016). They can possibly increase "equality in mobility" by allowing groups such as the physically challenged and the aged to make use of cars. Moreover, they free up time for commuters to carry out additional tasks (Pudāne et al., 2019). Apart from these direct benefits, self-driving vehicles could change society in more fundamental ways. For instance, self-driving cars could adopt a sharing model and operate as "driverless taxis" eliminating the need for car ownership (Combs, 2019; Masoud and Jayakrishnan, 2016). Not only would such a system reduce the total number of cars, but it would also free up space in central urban areas by not requiring parking spaces. Milakis et al. (2017); Gruel and Stanford (2016) outline such ripple effects of self-driving vehicles. Unsurprisingly, Brynjolfsson and McAfee (2014) often refer to autonomous vehicles as an important element of what they call the "second machine age".

As with any such potentially paradigm-shifting development, a gradual and phased deployment is likely. Freight transport, more specifically, commercial trucking is often thought of as one of the most interesting early application areas for various reasons. First, there already exist successful implementations of autonomous vehicle technology in closed settings such as in warehouses or container terminals (Azadeh et al., 2019; Roodenbergen and Vis, 2001; Kim and Bae, 2004). Second, they reduce operating costs and increase hours of service leading to direct business savings for commercial fleet operators (Fritschy and Spinler, 2019). Companies have therefore begun developing and testing self-driving trucks (Hirsch et al., 2020; Frangoul, 2019; Tesla, 2019; Benz, 2015).

Despite the enormous investments, it is unlikely that autonomous trucks will be allowed on the road any time soon. Several safety concerns remain along with questions about security, privacy, and liability (Simpson et al., 2019; Fagnant and Kockelman, 2015). Consequently, legal and policy issues continue to exist (Slowik and Sharpe, 2018). Therefore, driver supervision would likely still be needed in the near future. Further progress in technology and testing would gradually reduce this requirement.

With cruise control and lane-keeping assist commercially available, further progress in technology points to platooning as the next step. Platooning is often seen as one of the most likely first steps in the roll-out of automated driving on public roads (World Maritime University, 2019). Platooning technology virtually connects a set of trucks to form a convoy with a leading truck and one or more following trucks at short headways. Following trucks may automatically manoeuvre based on the operation of the lead truck. With time and progressing technology, we may see platoons with drivers resting while being in the truck or even platoons in which not all trucks require drivers, thereby moving closer and closer to a 
society with fully autonomous self-driving vehicles (Kilcarr, 2016). Various companies have conducted real life tests in different parts of the world (Eckhardt et al., 2016; Ministry of Transport - Singapore, 2017; Tsugawa, 2014).

Truck platooning and related automotive technologies will change the job of truck drivers by gradually taking over more and more tasks. Truck drivers' acceptance of these developments is important not only for the future of platooning but for that of automated driving in general. An implementation of this technology without considering driver views could leave them feeling disgruntled (Brown et al., 2002), slowing down the adaptation of automated driving in the process. The abundance of literature on technology acceptance in many areas shows the necessity of such research. We provide a brief overview of this literature stream in Section 2. The current driver shortages only increase the importance of exploring drivers' anticipation of this new technology, and their views on how it would affect their job (satisfaction). (Müller, 2020; Costello and Suarez, 2015)

In the platooning literature, most work has done been from the perspective of technology (Bergenhem et al., 2012; Maiti et al., 2017), safe manoeuvring of platoons (Kavathekar and Chen, 2011), human factors (Heikoop et al., 2017; Hjamdähl et al., 2017; Larburu et al., 2010)) and transportation optimization (Bhoopalam et al., 2018). A few research efforts such as Castritius et al. (2020); Yang et al. (2018); Fröhlich et al. (2018); Richardson et al. (2017) look at driver acceptance of platooning technology focusing on the first phase of deployment in which drivers still need to be present and attentive in all trucks of the platoon. However, the potential benefits of this first phase in terms of cost savings appear to be small in practice (Daimler, 2019). Therefore, we go beyond simple platooning and consider more advanced forms of vehicle automation in which drivers in the following trucks may rest or in which drivers are not needed in the following trucks. In the latter setting, there is only a driver in the first truck of the platoon. These more advanced forms clearly have a big impact on the work of the truck drivers, creating a need to understand their acceptance of such more radical technological change.

To the best of our knowledge, we are the first to study driver acceptance of these more advanced forms of autonomous driving technology and platooning. Given this gap, we look at these developments from an open-ended and exploratory perspective. We believe the lack of knowledge in this domain precludes any more specific quantitative or theory testing research. Therefore, we aim to open the pathway towards more concerted, quantitative, and confirmatory research efforts in the area and consequently contribute toward the implementation of automated driving. More specifically, our contribution is twofold - (i) we explore the various perceptions of drivers on the different forms of truck platooning and (ii) we explore the range of driver perspectives regarding the advantages and disadvantages of the different forms of 
truck platooning for their jobs.

The rest of the paper is structured as follows. In Section 2, we review the technology acceptance literature with a focus on transportation. Following this, we explain our research methods and data collection in Section 3. Then, we go into our findings in Section 4 and discuss these findings in Section 5. We conclude the paper in Section 6.

\section{Relevant literature}

There is a large body of literature on technology acceptance. The basic framework most often used to study the acceptance of a new technology is the Technology Acceptance Model (TAM) developed by Davis (1989). Several studies like Marangunić and Granić (2015); Bagozzi (2007); King and He (2006); Ma and Liu (2004); Lee et al. (2003); Szajna (1996) provide extensive overviews of TAM research. Our current work could inform and assist in the design of more specific TAM research for the advanced platooning forms.

The digitization and automation of work has received a lot of attention. The acceptance of information systems technology has been studied in multiple contexts such as office automation (Marquié et al., 1994; Hardin, 1960a,b), sales (Buttle et al., 2006; Morgan and Links, 2001), healthcare (Ziefle and Valdez, 2017; Pino et al., 2015; Hu et al., 2015; Pai and 1 Huang, 2011; Wilkowska and Ziefle, 2011; Walter and Lopez, 2008), education (Park and Han, 2016; Al-Emran et al., 2018; Almaiah, 2018). Moreover, there is a large stream of research that focuses on industrial automation - for instance, in domains of automobile manufacturing (Faunce, 1960), power plant operation (Mann and Hoffman, 1960), and industrial production (Haddad, 1996; Walker, 1957). In this context, Argote et al. (1983) and Haddad (1996) point out that technology could reduce social interactions and level of autonomy in a job, potentially leading to alienation and stress.

In transportation, most technology acceptance research focuses on passenger and private transport. This includes automated public transport (Madigan et al., 2017; Alessandrini et al., 2014), bicycle sharing (Fan and Zheng, 2020; Kaplan et al., 2015), and even air travel (Rice et al., 2019; Bouwens et al., 2018). When it comes to private vehicles, acceptance research began growing in prominence in the early noughties and has been progressing alongside the technology - with earlier studies looking at advanced driver assistance systems like cruise control and speed assist (Wiethoff et al., 2002; Marchau et al., 2001) to more recent studies looking at self-driving cars (Raue et al., 2019; Robertson et al., 2017; Daziano et al., 2017; Schoettle and Sivak, 2014); see Becker and Axhausen (2017) for a literature review.

In contrast, the body of literature focusing on commercial drivers is smaller and more recent. Ghazizadeh et al. (2012) find that trust in technology is a major determinant in drivers' willingness to use on-board monitoring systems. Similar conclusions are drawn by 
Richardson et al. (2017) who also point out that drivers are afraid of being made redundant. As indicated in Section 1, a handful of studies look at the first phase of platooning technology, where drivers in all trucks need to be present and attentive at all times. Neubauer et al. (2019); Fröhlich et al. (2018) both encounter skepticism from drivers for reasons similar to those pointed out by Richardson et al. (2017). Castritius et al. (2020); Yang et al. (2018) take an additional step and check acceptance of drivers before and after they have experienced platooning technology. They find drivers to be more open and accepting after having experienced working with the technology.

\section{Research methods and design}

Our research focuses on an emerging technology that has not received much attention from the truck driver perspective. As a result, it is not clear how the people that have to work with the new technology perceive and evaluate the developments. Focus groups are a suitable method of data collection in such exploratory settings (Sutton and Arnold, 2013).

The group dynamic among participants in a focus groups fosters the generation of new ideas that might not have been thought of previously or otherwise, even by the researcher (see Morgan (1996); Kitzinger (1994, 1995)). This may help participants shape their ideas during the discussion and, as a result, contribute more meaningfully. Moreover, the open ended nature of focus groups ensures that the researchers' preconceived notions do not bias the outcomes. Furthermore, gathering information from participants in focus groups is more time-efficient compared to one-on-one settings such as interviews.

Focus groups are a common research method in technology acceptance research (Ziefle and Valdez, 2017; Park and Han, 2016; Pino et al., 2015; de Barcellos et al., 2014; Zaunbrecher et al., 2014; Wilkowska and Ziefle, 2011) and in transportation (Pudāne et al., 2019; Maréchal, 2016; Simons et al., 2014, 2013; Coughlin, 2001; Yassuda et al., 1997). Prior interviews often help in structuring and designing focus groups (Sutton and Arnold, 2013). Therefore, we use a combination of interviews and focus groups in our study.

\subsection{Research design}

During the research design, we conducted semi-structured interviews with several experts from a Dutch research consultant group involved in managing national platooning projects such as CATALYST (Janssen et al., 2020) and ENSEMBLE (Ensemble, 2018). We structure the focus group design around the different levels of automation and associated involvement of drivers based on Bhoopalam et al. (2018). We briefly describe them below -

Human driven platooning (HDP). All drivers in a platoon are required to be 
attentive at all times. The drivers in the following trucks receives assistance in the operational tasks such as braking and/or steering tasks but is still in control of the tactical driving tasks such as determining when to change lanes, turn or use signals etc.

Human driven platooning with in-platoon resting (HDP-IP). Drivers in the following trucks may rest during the platoon as the following trucks can handle all driving tasks. This could mean that the time as part of the platoon does not count as formal driving time for the driver in the following trucks.

Hybrid platooning (HP). This type of platooning allows the removal of drivers from one or all the following trucks in a platoon. Drivers would still need to be present when a truck is outside of the platoon. Therefore, drivers may need to be shuttled around between meet/split points of platoons to drive individual trucks to/from these points.

Existing platoon literature that we described in Section 2 focuses on HDP. We also consider the platooning forms associated with more advanced levels of automation. Table 1 provides an overview of the questions used in our focus groups. The questions are grouped into several categories. The first category serves as an introduction and is meant to get an idea of how drivers perceive their jobs and the way that any recent technology has changed their work. The following three categories correspond to the different forms of platooning. The questions across the different categories are mostly consistent with HDP and HDP-IP having some additional specific ones related to their respective characteristics. To conclude, participants were asked how they thought platooning technology would affect transport companies.

\subsection{Recruitment and data collection}

As is common in focus group research (see Wilkinson and Silverman (2004)), we conducted five focus groups in total. These focus groups took place in the Netherlands in the period between May 2019 and February 2020, i.e., before the Coronavirus pandemic. Each focus group had 4 to 7 truck drivers with a total of 25 drivers across the groups; 24 males and one female. The drivers had an average age of 46.2 years with the oldest being 63 and the youngest 25. The drivers worked for different transport companies and transported different loads, e.g., containers, bulk or garbage. Some drivers only performed transportation trips within the Netherlands while others performed longer international trips. None of the drivers had any prior experience with platooning technology. We provide information on these drivers in A. The focus groups had an average duration of approximately 75 minutes with the longest one taking 90 minutes.

To carry out these focus groups, we visited three truck stops in the Netherlands; at the Port of Rotterdam, in Vuren, and in Vlaardingen. In particular, we visited truck stops with 


\section{Introduction}

Who are you and what is your job?

What does your typical day at work look like?

Have you had to get used to any new technology at your job? How did it make your job different (easier/harder)?

\section{Human driven platooning}

Do you think this will become a reality? When?

Let's say it does become a reality. How would it affect the way you do your job?

What do you think the benefits of this are for you?

What are the drawbacks of this for you?

\section{Human driven platooning with in-platoon resting}

Do you think this sort of platooning will become a reality? If so, when?

How will this further development in the technology affect the way you do your job?

What do you think the benefits of this are for you?

What are the drawbacks of having this for you?

How would you like the truck cabin interior to be if you had to take a break in it?

Apart from taking breaks, what kind of other activities do you think you could do in a following truck?

\section{Hybrid platooning}

Do you think this sort of platooning will become a reality? If so, when?

How will this further development affect the way you do your job?

What do you think the benefits of this are for you?

What are the drawbacks of having this for you?

In such a scenario, would you prefer being the leader of a platoon or someone that mainly does first/last mile trips?

Final thoughts

How do you think platooning will affect your company if it does become a reality?

Table 1: Focus group questions 
restaurants where truck drivers spend their evenings after their work day. We approached truck drivers and asked if they would be willing to participate in our focus group. With sufficient participants, we carried out the focus group session. There were two visits in which we did not succeed in recruiting enough truck drivers to form a focus group.

During the focus groups, the participants were shown slides explaining each form of platooning and were allowed to freely express their thoughts with the moderator guiding the discussion and keeping all participants involved. The focus groups were all carried out in Dutch.

\subsection{Data Analysis}

The audio from all focus groups was recorded, transcribed, and translated to English for analysis. We studied the data using content analysis (Neuendorf and Kumar, 2015). That is, the data from all focus groups was coded and patterns were identified to gain insights. Like Pudāne et al. (2019), our analysis is largely inductive but with some deductive elements based on insights from the literature.

\section{Findings}

We now go into the findings from our focus groups. Findings will be accompanied by quotes from drivers where relevant.

\subsection{Job satisfaction}

In general, the drivers were proud of their work and felt that it brought them fulfillment. The drivers find it attractive to be on the road for long periods of time. While on the road, they especially appreciate their perceived freedom and autonomy. Furthermore, they find their jobs to be eventful as they move between different locations and meet different people along the way. These findings are consistent with earlier studies on truck driver job satisfaction (Johnson et al., 2011; Stephenson and Fox, 1996). Several drivers argued that it was hard to explain the joys of their work to someone outside the profession.

"I like everything [about the job] but I don't really know why. You grow up with it. It is just your thing. It is your life" (Rudy) "It [truck driving] is a hobby for me." (John)

"You should see it [truck driving] as a hobby, otherwise it won't work." (Jan)

Viewing the profession as a hobby was seen as a necessity by drivers in order to deal with the negative sides of the job. The above mentioned positives often come with caveats such as 
being away from home and by yourself for extended periods or constantly having to deal with traffic. Traffic related frustrations include the 'anti-social' driving behavior of surrounding civilian traffic, that is, car drivers do not consider the sheer mass of a truck and treat it as just another car that can brake quickly when, for instance, a car would abruptly change lanes in front of them. As a result, nearly every truck driver had experienced some close calls on the road. The recently rising traffic levels have exacerbated this.

"And what I find very annoying at work is antisocial driving behavior. Selfish driving behavior. Just people who always want to get past a traffic jam. Then they are at the wrong place" (Robert)

"How people feel about you. That people have absolutely no respect for you on the street"

(Shawn)

Apart from traffic concerns, drivers felt their jobs negatively impacted their social lives. Their jobs did give them the chance to meet other drivers and employees at the various locations they visited but it did take away the time with friends and family. These factors for dissatisfaction are in line with studies exclusively looking at truck driver job satisfaction in different parts of the world such as the United states (Fields, 1998; Mittal et al., 2018), China (Jiang et al., 2017), India (Mittal et al., 2018), the Netherlands (De Croon et al., 2002).

Some of the more recent job-related concerns were about the decrease in autonomy and freedom mainly due to recent developments in technology, which leads us to the next section.

\subsection{Experiences with new technology}

One of the technologies that has had the most profound impact on the work of the truck driver over the last two decades is the tachograph. A digital tachograph continuously tracks speed, driving periods, and breaks. For many drivers in our focus groups, the introduction of the tachograph represented a significant shift from the days when employers could only reach them on fixed telephones at certain locations. As employers constantly monitor the drivers, the drivers perceive less freedom and autonomy.

"But everything is planned exactly that way. It was not like this. They know that he [the driver] will arrive at this time and that he will be ready at that time. Everything is planned. The people are so focused and stressed, including the drivers, because they have to be exactly on time. That was not the case at the time." (Adam)

Together with an on-board computer, many administrative tasks are now accomplished electronically which the drivers argue means that they have less social interaction. 
"Now we no longer communicate [with people at drop-off location]. It is just click and press, we are no longer in contact. We don't really talk to each other anymore at the terminal. This [use the tachograph] is really all I do. This is the only time this whole week that I talk to someone." (John)

Drivers have also get used to ABS (Anti-lock Braking System) and EBA (Emergency brake assist), which the overwhelming majority of the focus group drivers agreed was good and added to safety. In general, they felt that ABS did not fundamentally change their driving tasks. Some drivers however did not trust it since they felt it, on occasion, intervened at inappropriate times. This left them feeling they were not in control of the truck any more, and therefore unsafe.

"The system sometimes intervenes too quickly. I drove through Eindhoven on Monday and I was braking, gently braking. But it [EBA] did not not think it was hard enough. That thing just went off" (Simon)

Another new technology that drivers mentioned was Adaptive Cruise Control (ACC). ACC in a vehicle automatically adjusts its speed to maintain a certain distance to the vehicle ahead. This is particularly relevant since platooning uses a more advanced version where all trucks are virtually connected. The majority opinion in the focus groups towards ACC seemed to be positive with drivers acknowledging it makes their tasks easier and safer.

"That is one great thing, that distance system [ACC]. You can just text while driving, now you can do everything. It couldn't be safer. You turn that thing on and you don't bump into anything" (James)

The above quote indicates a possible unintended consequence of having ACC. Texting while driving is clearly unsafe and therefore illegal in the Netherlands (Ministry of Infrastructure and Water Management, 2019). The driving task with ACC demands less attentiveness from drivers leaving them room to focus on other tasks, which might have an adverse effect on traffic safety in certain sudden and unexpected situations (see Brookhuis et al. (2019)).

We now segue into the more specific discussions on platooning. We organize the following sub-sections based on the different forms of platooning.

\subsection{Implementation of platooning}

Citing the developments they have already seen and experienced, drivers believe that the different levels of platooning would make their way to public roads in the future. They did, however, have very different estimates on the expected timeline. A few drivers thought that 
the initial phases are already here - the trucks are just not virtually connected to each other. On the other hand, some other drivers, pointing to legal and regulatory processes, suggested it will take more than ten years before HDP would become a reality.

"And with that modern technology, that $A B S$, you actually already have that. You are all on the cruise control and that distance regulator. The car actually takes care of it. I think you are very much in the initial phase now." (Harry)

"Yes, the system is already there, but I think it is still early. I think it will take 10-15 years. Then they are already a lot of steps further" (Jay)

When it came to the timeline of HDP-IP, drivers thought it would appear about 5-10 years after HDP because of special infrastructure plausibly being required. Moreover, driving time regulations would need amending adding to the regulatory to-do list. The next step, HP was seen by drivers as something they would not experience since they would have retired by the time it would become a reality.

"This [HP] is absolutely going to happen. Whether we will experience it? - Let me put it this way, then we are really already 25 years in the future. (Robert)

In the conversations about implementation, drivers also pointed out the usefulness of platooning would vary based on location - that is, platooning is likely to be implemented sooner in larger countries such as the United States or Australia. The longer distances there provide more opportunities for platooning. In smaller countries like the Netherlands, the distances between stops for trucks tend to be quite short, which means that the benefits are likely to be offset by the costs of forming a platoon. Furthermore, in a compact country like the Netherlands, the traffic tends to be denser with more interruptions from vehicles joining and leaving highways. As a result, the benefits of platooning here are likely to be lower. This is even more applicable to the more advanced forms - HDP-IP and HP- since longer distances are key for the benefits they provide.

"And we do not have those [long] distances. These [HDP-IP and HP] are very beautiful ideas. Hooking up hops. They have been busy with a system through the guardrail, but it does not work. I don't see this succeeding either. (Martin)

"Plus, we're talking about one stop now. How many trucks are driving in the Netherlands that have at least 12-14 stops in a day." (Martin)

Drivers also indicated that the achievement of a critical mass is essential for platooning to be a success, that is, it would work only if a lot of trucks are able to participate and collaborate. Drivers pointed out that a specific organization may need to manage the formation of platoons. This is similar to the idea of a platoon service provider (see Janssen et al. (2015)) 
"Then you only get one transport company in the whole of the Netherlands or Europe that takes care of all trucks, because otherwise it [HP] is not possible. I can't just get on his

truck, because I only have a permit for my company" (Daan)

\subsection{Driving in a platoon in traffic}

None of the drivers from the focus groups had prior experience of driving in a platoon. Citing the high traffic density in the Netherlands, drivers expressed their concerns about trusting platooning technology to handle some of the complicated traffic situations they have experienced. This is exacerbated by the "anti-social" driving behaviour of surrounding traffic. Drivers recounted instances of some of their close calls in traffic.

"On that specific trajectory [from the port to the highway] you are passing multiple exits. Basically all trucks that merge onto the highway are fully loaded. Since the road is elevated, the speed of the vehicles is low when they merge. How does this influence other road users? That's something to take into account. I would be uncomfortable on such points. That my truck is going to decide things." (Rudy)

Some drivers however, did point out that if the technology would be reliable, it would lead to more relaxed driving - especially in a high traffic situations which can often be stressful. This was not the case with the more advanced forms of platooning. With HDP-IP, drivers found the idea of not being attentive and in control while being in the following truck hard to imagine. Given the repercussions of a potential accident, they would not be comfortable resting and posited that drivers should always be attentive.

"Surely you do not believe that I am going to sleep on a bed in such a moving thing [truck]. Well, certainly not." (Adam)

There is also the human aspect. You are in a convoy ten meters behind the truck in front of you, and you are going to close your eyes? No, you cannot do that." (Simon)

HDP-IP introduces another dimension of trust. Drivers in the following trucks now need to trust the lead driver in addition to the technology, which they would find difficult to do. This was again because of the repercussions of a potential accident.

"Then you have to put your trust completely in the front driver. I have some trouble with that." (Tim)

When it came to trusting technology, drivers preferred HP- driving the lead truck in such a platoon. This is because this would be closest to driving a truck the way they do currently, 
only with extra load at the back (in the form of follower trucks). They would not have to give away too much of their driving task to the system this way. One driver pointed out that this form of platooning makes most sense from the drivers' perspective since it eliminates all the qualms a following driver might face. They therefore suggested the previous forms of platooning be skipped. This is similar to the argument for skipping SAE level 3 in the context of automated passenger cars (see Auto2x (2019)).

For all forms of platooning, drivers said that it is important that trucks in a platoon are ordered correctly and safely. For instance, brake power and mass of a truck would determine how quickly it can stop in an emergency situation and a truck that can do so quicker best belongs at further behind in the platoon. Nowakowski et al. (2015) suggest having trucks in ascending order of engine power to mass ratio.

\subsection{Effects of platooning on a driver's job}

Drivers discussed how platooning could affect their jobs at length in the focus groups. Drivers expected to see many changes in their work days due to platooning. We structure these effects of platooning on their jobs into four interrelated categories - (i) pleasure/satisfaction of work, (ii) freedom/autonomy in their work, (iii) relationship with their employers, (iv) nature of tasks they perform.

(i) Pleasure/satisfaction of work - As we discussed in Section 4.1, many truck drivers truly enjoy their work. They viewed platooning as something that would negatively affect their work by making it more monotonous and less fun. As platooning technology takes over several driving tasks, it reduces the fulfillment of driving.

"I just want to drive, I want to drive myself. My passenger car is an automatic, I think that is very different in terms of technology, but I think in a truck I just like switching gears myself. Sure, I sometimes had a painful leg in the traffic jam and it is also more tiring, but on the other hand I think it is a lot nicer." (John)

"No, then it will be a very long and boring day. Then you have nothing to do" (Max)

(ii) Freedom/autonomy in their work - Being their own boss was something the truck drivers truly appreciated. Although recent developments in technology (see Section 4.2) have reduced the autonomy drivers perceive, they are still largely independent while on the road. Platooning, however, would further reduce their autonomy. Not only does it take over parts of their their driving tasks, but it also makes their driving schedules stricter. That is, drivers would have to follow tight guidelines to be able to meet up with other trucks to form platoons. 
"You have even less control. And again a piece of freedom that you have to hand in."

(Paul)

"And you are no longer your own boss. And then a computer will work with our machine. That does not make anyone happy. Every driver sitting here thinks this. You should not touch our machine. And I think that is the most important point. Then there is no more work for us." (Robert)

"We started working and we got the tachograph. Then we got a smarter tachograph and now we get an even smarter tachograph. We keep doing it because you can accelerate yourself. But when that is no longer there, there is really nothing left." (Daan)

As expected, this is aggravated by the increase in automation, that is, more advanced the form of platooning, the more freedom drivers lose. For instance, HDP-IP might cause drivers to even give up their traditional breaks for mandated ones in the truck. This would further increase their workloads. HP would imply that drivers must drive different trucks at different times, which means they have to give up their own personal truck. Being able to drive in their 'own' truck is very important for many drivers.

Why would you want that [HDP-IP]? We already work an average of 13 hours a day. (Andrew)

"Then you are in someone else's truck. Because that is still being ignored. It [our truck] is our house. You live in it all week and that [driving different trucks at different times] will not work." (Yohan)

(iii) Relationship with their employers - Drivers opined that their employers would enjoy the bulk of platooning benefits as it reduces costs. In addition, drivers expressed concerns that employers would not value their work the same anymore, that is, employers may argue that the drivers now work less since the technology takes over a big portion of the driving task. As a result, they were afraid that they may be paid less. Again, these concerns were more vocally expressed for the more advanced forms of platooning. As discussed, with HDP-IP, employers might ask drivers to work longer days without appropriate compensation. This sentiment, that 'freeing up time' would actually exacerbate stress and time pressure, echoes results from a focus group study held in the context of self-driving cars: Pudāne et al. (2019) found that travelers anticipated that when others (e.g. employers) would know that they could spend time working when driving, this would be taken advantage of at the expense of the traveler.

"Yes, so you would not come home at all anymore. And probably for less pay, because you work less according to the boss. (Andrew) 
In the case of HP, employers may claim that the time spent shuttling drivers around between the meet/split of platoons is not actually work and not compensate them for it.

"Because what will the boss say when the driver gets out of the car: I'm not going to pay you anymore. So that driver has to be driven to another place in a van. Those hours are not paid and then it is again at the expense of the driver." (Robert)

(iv) Nature of tasks they perform - Drivers perform a variety of tasks during the day apart from driving - such as administrative work, loading or unloading etc. Platooning technology could shake up the proportion of time drivers spend on each of them - mostly the advanced forms which do not require the drivers attention at all times. HDP-IP would change the way drivers spend time in their trucks - they could take breaks but also engage in other tasks. This could be entertainment related such as watching movies, work related such as doing some administration work, or related to personal development such as following a course.

"Administration. Maybe you can put a planner on such a truck. You are you planning for each other. Saves office building again" (Grant)

"Maybe you are going to study or something. But yes, you still have to pay attention." (Gabriel)

The first quote above points to potential future business practices. Furthermore, drivers themselves could take on additional roles such as handling calls, planning, and so on (Glaeser, 2007).

HP would significantly change the way drivers spend time outside of the truck. Apart from having to be shuttled around, drivers may have to perform more loading and unloading tasks. When all the trucks in a platoon are headed to the same destination (or start at the same origin), drivers will likely be responsible for the unloading (or loading) of all trucks in question. Drivers were not enthusiastic about this eating into their time they spend driving since it is the activity they enjoy the most. This is in line with Wijngaards et al. (2019) who find drivers significantly prefer driving over pick up and delivery tasks.

"Then I will drive three trucks, but indeed if I have to unload three trucks, how much time do I spend driving back and forth?" (Andrew)

\subsection{Effects of platooning on the trucking industry}

Throughout the focus group discussions, drivers spoke out on how they thought platooning would affect their companies and the trucking industry. We briefly touched upon these 
ideas in the previous section while discussing the relationship of drivers with their employers. Drivers saw clear benefits of platooning for a trucking company and therefore were fearful of being taken undue advantage of. For a company, drivers thought there were clear (financial) benefits -

"It is cost effective and it will benefit a company. Less fuel, tires, brakes. So in that respect you could take advantage of it." (Shawn)

As a result, they argued companies would push for it and others eventually follow. Platooning technology requires an investment giving larger trucking companies an opportunity to strengthen their hold on the market by offering cheaper services to clients. Smaller companies and independent truck drivers would suffer and could potentially be driven out of business.

"So as a small company you will lose the battle, because you will no longer accept it. Large companies may already have a lot of that [platooning] knowledge. That is how it is going to happen. As a small business owner, you will really lose this battle. I am convinced of that."

"I think that small businesses of up to 40-50 trucks can all leave and that you will only count if you have around 100 trucks" (Paul)

Therefore, if left completely unregulated, drivers expected that larger and financially stronger trucking operators and logistics service providers would take over the industry.

\section{Discussion}

The findings suggest that truck drivers are generally not positive about the implications of platooning technology on their work environment. Broadly speaking, this is because of three factors - (i) a lack of trust in the technology, (ii) the fear of their profession becoming redundant, and (iii) the technology interfering with the nicest part of their job - driving.

As for HDP, this negative sentiment stemmed mostly from a lack of trust in the technology. Previous research has reported similar results (Neubauer et al., 2019; Fröhlich et al., 2018). However, studies have shown that drivers become more receptive and accepting once they have experienced driving in a platoon (Castritius et al., 2020). The positive outlook towards ACC from the drivers in our focus groups suggest that they might also be similarly accepting towards HDP since one can reasonably argue that it is more advanced form of ACC. Furthermore, the fear of being made redundant is not very strong since drivers still need to be active and have a major role to play. 
However, the same cannot be said for the more advanced forms of platooning, where all of these factors play a greater role. Drivers found it even harder to trust this more disruptive technology since they would have ceded control. In addition, while HDP might affect a driver's task on certain sections of their route, HDP-IP and HP would potentially change the fundamental nature of a truck driver's job while slowly decreasing their levels of involvement and control. The system takes over a sizeable part of the decision-making process, which generally decreases acceptance (Bekier and Molesworth, 2017). The drivers viewed these more advanced forms as something that interfered with the true essence of being a truck driver. These negative views of drivers toward platooning seem to support (Pink, 2011) who argue that that autonomy is a key driver of intrinsic motivation. Such observations were made even in the context of industrial automation where a reduction in autonomy lead to an increase in stress and alienation (Haddad, 1996; Argote et al., 1983).

Furthermore, this could come with a potential increase in the number of "working" hours (number of hours they need to spend at their job) with inadequate financial compensation. As the system slowly takes over more tasks, it might dissect a truck drivers job into activities that each carry a different value and require a different skill. A possible consequence is that drivers are employed only for those activities they add value to. The other activities could either be automated or performed by lower wage workers. This could indicate the advent of Taylorism (see Taylor (1911)), which the trucking industry has largely escaped thus far (Aho, 2018).

With this progression, the job description of a truck driver might look different in the future. Such trends are already visible in certain areas - for example, ports and terminals. Gekara and Thanh Nguyen (2018) conclude that automation has created new roles in addition to displacing and transforming the more traditional operations ones, with a greater focus on soft skills and computer proficiency. This calls for a rethinking of training and education (Nedelkoska and Quintini, 2018), something which the drivers indicated as well.

It is impossible to make accurate predictions about the acceptance and use of future technologies based on focus group research alone. Rather, much additional research is necessary especially to study post-experience acceptance. Given the pace of development of technology, it is plausible that the advanced platooning forms become a reality in the not too distant future. One can use the insights from this study to conduct a study similar to that of Castritius et al. (2020) for the advanced forms.

Castritius et al. (2020) postulate that drivers with a general positive attitude towards technology would be more willing to use platoon technology. Many of the drivers that drive trucks in platoons may come from the next generation, which is likely to be more positive towards technology (Olson et al., 2011). Furthermore, in this future generation, the decision to 
join the trucking industry as a 'driver' in a platoon would be based on different expectations, compared to the current generation of drivers who might feel that platooning technology is being forced upon them. However, it is unclear whether their attitude towards platooning will be more positive since the technology takes away what many consider to be the enjoyable parts of the job and reduces autonomy. In any case, drivers would need to undergo adequate training and education before being able to drive platoons. In general, drivers that took part in our focus groups had a limited prior understanding of how platooning works. Therefore, it might be in a company's best interests to inform drivers thoroughly on these developments early in the planning phases. As indicated, drivers thought that platooning will become a reality in any case and involving them in the planning phases would provide relevant input for a smooth implementation of the technology and it could possible lead to higher levels of acceptance by gradually adjusting expectations.

Another perspective that deserves further study, is that of labor relations at an industry

level. In the past, rapid automation of industries coincided with particularly heated debates and fraught relations between employers and employees, e.g. triggering the founding of unions in the late nineteenth and early twentieth century. The trucking industry, which is traditionally heavily unionized, could prove a particularly alluring 'battleground' for those with strong views on the automation of tasks customarily performed by humans. As such, a sociological perspective on the broader impacts of platooning on the trucking industry as a whole, is an important avenue for further research into this emerging transport technology.

\section{Concluding remarks}

The advent of self-driving cars is quickly approaching. As a result, there has been a growing body of research that tries to better understand the different elements that are important for the implementation. We contribute to this body of literature by looking at one of the most likely first implementations of automated driving in an open environment - truck platooning. The aim of this study was to explore the range of opinions about platooning among truck drivers - particularly for the more advanced forms of platooning in which drivers may take a break or be removed from following trucks. To this aim, we conducted a series of focus groups in the Netherlands by visiting truck stops across the country. Drivers in general appear to be fairly negative about using platooning technology since they found it intrusive and hard to trust. Furthermore, they felt it would take away their autonomy and leave them open to exploitation. Further research where drivers actually experience the technology, perhaps by means of a simulator or real-life small scale pilots, would provide valuable insights into the subtle and multi-faceted effects that various specifications of truck platooning technologies might have on how truck drivers perceive and value their job and their interaction with this 
emerging technology.

\section{Acknowledgements}

We would like to thank Rob Zuidwijk (Erasmus University Rotterdam) and Eric Molin (TU Delft) for their feedback and comments during the design of the focus group and their comments on earlier versions of the paper. We also thank Robbert Janssen, Thijs van Engelen, and Sarah de Koff (TNO) for being the expert interviewees in the interviews we conducted prior to the focus groups.

Funding: This work was supported by the Netherlands Organization for Scientific Research (NWO) as part of the 'Spatial and Transport impacts of Automated Driving (STAD)' [Project number 438-15-161] project.

\section{References}

Aho, T., 2018. Driving through neoliberalism: Finnish truck drivers constructing respectable male worker subjectivities, in: Masculinity, Labour, and Neoliberalism. Springer, pp. 289-310.

Al-Emran, M., Mezhuyev, V., Kamaludin, A., 2018. Technology acceptance model in m-learning context: A systematic review. Computers \& Education 125, 389-412.

Alessandrini, A., Alfonsi, R., Delle Site, P., Stam, D., 2014. Users' preferences towards automated road public transport: results from european surveys. Transportation Research Procedia 3, 139-144.

Almaiah, M.A., 2018. Acceptance and usage of a mobile information system services in university of jordan. Education and Information Technologies 23, 1873-1895.

Argote, L., Goodman, P.S., Schkade, D., 1983. The human side of robotics: How worker's react to a robot. Sloan Management Review .

Auto2x, 2019. Volvo to skip level 3 autonomous mode. URL: https://auto2xtech.com/volvo-to-skip-level-3-autonomous-mode/.

Azadeh, K., De Koster, R., Roy, D., 2019. Robotized and automated warehouse systems: Review and recent developments. Transportation Science 53, 917-945.

Bagozzi, R.P., 2007. The legacy of the technology acceptance model and a proposal for a paradigm shift. Journal of the Association for Information Systems 8, 244-254. 
de Barcellos, M.D., Kügler, J.O., Grunert, K.G., Wezemael, L.V., Pérez-Cueto, F.J.A., Ueland, Ø., Verbeke, W., 2014. European consumers' acceptance of beef processing technologies: A focus group study. Innovative Food Science \& Emerging Technologies 11, $721-732$.

Becker, F., Axhausen, K.W., 2017. Literature review on surveys investigating the acceptance of autonomous vehicles. TRB 96th Annual Meeting Compendium of Papers .

Bekier, M., Molesworth, B.R.C., 2017. Altering user'acceptance of automation through prior automation exposure. Ergonomics 60, 745-753.

Benz, M., 2015. The long-haul truck of the future. URL: https://www.mercedesbenz.com/en/innovation/autonomous/the-long-haul-truck-of-the-future/.

Bergenhem, C., Schladover, S., Coelingh, E., 2012. Overview of platooning systems, in: Proceedings of the 19th ITS World Congress, Oct 22-26, Vienna, Austria (2012).

Bhoopalam, A.K., Agatz, N., Zuidwijk, R., 2018. Planning of truck platoons: A literature review and directions for future research. Transportation Research Part B: Methodological 107, 212-228.

Bouwens, J.M., Fasulo, L., Hiemstra-van Mastrigt, S., Schultheis, U.W., Naddeo, A., Vink, P., 2018. Effect of in-seat exercising on comfort perception of airplane passengers. Applied Ergonomics 73, 7-12.

Brookhuis, K.A., De Waard, D., Janssen, W.H., 2019. Behavioural impacts of advanced driver assistance systems-an overview. European Journal of Transport and Infrastructure Research 1.

Brown, S.A., Massey, A.P., Montoya-Weiss, M.M., Burkman, J.R., 2002. Do I really have to? User acceptance of mandated technology. European Journal of Information Systems $11,283-295$.

Brynjolfsson, E., McAfee, A., 2014. The second machine age: Work, progress, and prosperity in a time of brilliant technologies. WW Norton \& Company.

Buttle, F., Ang, L., Iriana, R., 2006. Sales force automation: review, critique, research agenda. International Journal of Management Reviews 8, 213-231.

Castritius, S.M., Hecht, H., Möller, J., Dietz, C.J., Schubert, P., Bernhard, C., Morvilius, S., Haas, C.T., Hammer, S., 2020. Acceptance of truck platooning by professional drivers on german highways. a mixed methods approach. Applied ergonomics 85, 103042. 
CB Insights, 2020. 40+ Corporations Working On Autonomous Vehicles.

Combs, V., 2019. How autonomous vehicles will change car ownership. URL: https://www.zdnet.com/article/how-autonomous-vehicles-will-change-carownership/.

Costello, B., Suarez, R., 2015. Truck driver shortage analysis 2015. Arlington, VA: The American Trucking Associations .

Coughlin, J., 2001. Transportation and older persons: Perceptions and preferences. Technical Report. Center for Transportation Studies and Age Lab, Massachussetts Institute of Technology.

Daimler, 2019. Daimler trucks invests half a billion euros in highly automated trucks. URL: https://media.daimler . com/marsMediaSite/en/instance/ko/Daimler-Trucksinvests-half-a-billion-Euros-in-highly-automatedtrucks . xhtml?oid=42188247.

Davis, F.D., 1989. Perceived usefulness, perceived ease of use, and user acceptance of information technology. MIS Quarterly 13, 319-340.

Daziano, R.A., Sarrias, M., Leard, B., 2017. Are consumers willing to pay to let cars drive for them? analyzing response to autonomous vehicles. Transportation Research Part C $78,150-164$.

De Croon, E.M., Blonk, R.W., De Zwart, B.C., Frings-Dresen, M.H., Broersen, J.P., 2002. Job stress, fatigue, and job dissatisfaction in dutch lorry drivers: towards an occupation specific model of job demands and control. Occupational and environmental medicine 59, $356-361$.

Eckhardt, J., Aarts, L., van Vliet, A., Alkim, T., 2016. European truck platooning challenge 2016, lessons learnt.

Ensemble, 2018. Platooning together. URL: https://platooningensemble.eu/.

Fagnant, D.J., Kockelman, K., 2015. Preparing a nation for autonomous vehicles: opportunities, barriers and policy recommendations. Transportation Research Part A: Policy and Practice 77, 167-181.

Fan, Y., Zheng, S., 2020. Dockless bike sharing alleviates road congestion by complementing subway travel: Evidence from beijing. Cities 107, 102895. 
Faunce, W.A., 1960. Social stratification and attitude toward change in job content. Social Forces , 140-148.

Fields, D., 1998. Keeping the "shiny side up" and the "hammer down": The subculture of american truck drivers. Thesis - Western Kentucky University .

Frangoul, A., 2019. Self-driving trucks are being tested on public roads in virginia. URL:

https://www . cnbc.com/2019/09/10/self-driving-trucks-are-being-tested-onpublic-roads-in-virginia.html.

Fritschy, C., Spinler, S., 2019. The impact of autonomous trucks on business models in the automotive and logistics industry-a delphi-based scenario study. Technological Forecasting and Social Change 148, 119736.

Fröhlich, P., Sackl, A., Trösterer, S., Meschtscherjakov, A., Diamond, L., Tscheligi, M., 2018. Acceptance factors for future workplaces in highly automated trucks, in: Proceedings of the 10th International Conference on Automotive User Interfaces and Interactive Vehicular Applications, pp. 129-136.

Gekara, V.O., Thanh Nguyen, V.X., 2018. New technologies and the transformation of work and skills: a study of computerisation and automation of australian container terminals. New Technology, Work and Employment 33, 219-233.

Ghazizadeh, M., Peng, Y., Lee, J.D., Boyle, L.N., 2012. Augmenting the technology acceptance model with trust: Commercial drivers' attitudes towards monitoring and feedback, in: PROCEEDINGS of the HUMAN FACTORS and ERGONOMICS SOCIETY 56th ANNUAL MEETING - 2012, pp. 2286-2290.

Glaeser, E.L., 2007. Introduction, in: Glaeser, E.L. (Ed.), Agglomeration Economics. University of Chicago Press. chapter 1, pp. 1-14.

Gruel, W., Stanford, J.M., 2016. Assessing the long-term effects of autonomous vehicles: a speculative approach. Transportation research procedia 13, 18-29.

Haddad, C.J., 1996. Employee attitudes toward new technology in a unionized manufacturing plant. J. Eng. Technol. Manage. 13, 145-162.

Hardin, E., 1960a. Computer automation, work environment and employee satisfaction. Industrial and Labour Relations Review 13, 559-567.

Hardin, E., 1960b. The reactions of employees to office automation. Monthly Lab. Rev. 83, 925. 
Heikoop, D., de Winter, J.C.F., van Arem, B., Stanton, N.A., 2017. Effects of platooning on signal-detection performance, workload, and stress: A driving simulator study. Applied Egronomics 60, 116-127.

Hirsch, J., Trucks.com, Name*, 2020. Waymo begins testing autonomous heavy-duty trucks in texas. URL:

https://www.trucks.com/2020/08/25/waymo-autonomous-truck-tests/.

Hjamdähl, M., Krupenia, S., Thorslund, B., 2017. Driver behaviour and driver experience of partial and fully automated truck platooning - a simulator study. European Transport Research Review 9.

Hu, P.J., Chau, P.Y.K., Schend, O.R.L., Tam, K.Y., 2015. Examining the technology acceptance model using physician acceptance of telemedicine technology. Journal of Management Information Systems 16, 91-112.

Janssen, R., van Meijeren, J., Hendrickx, N., Schipper, C., Reudink, C., 2020. Robbert janssen, jaco van meijeren, nicolien hendrickx, caroline schipper, chris reudink. URL: https://dutchmobilityinnovations.com/spaces/1182/catalyst-living-lab/about.

Janssen, R., Zwijnenberg, H., Blankers, I., de Kruijff, J., 2015. Truck Platooning: Driving the future of transportation. Technical Report. TNO.

Jiang, C., Lu, L., Lu, J.J., 2017. Socioeconomic factors affecting the job satisfaction levels of self-employed container truck drivers: a case study from shanghai port. Maritime Policy \& Management 44, 641-656.

Johnson, J.C., Bristow, D.N., McClure, D.J., Schneider, K.C., 2011. Determinants of job satisfaction among long-distance truck drivers: An interview study in the united states. International Journal of Management 28, 203.

Kaplan, S., Manca, F., Nielsen, T.A.S., Prato, C.G., 2015. Intentions to use bike-sharing for holiday cycling: An application of the theory of planned behavior. Tourism Management $47,34-46$.

Kavathekar, P., Chen, Y., 2011. Vehicle platooning: A brief survey and categorization, in: ASME 2011 International Design Engineering Technical Conferences and Computers and Information in Engineering Conference, American Society of Mechanical Engineers. pp. 829-845. 
Kilcarr, S., 2016. Driverless trucks: Where they'll work, where they won't. URL: http://m.fleetowner.com/technology/driverless-trucks-where-they-ll-workwhere-they-won-t.

Kim, K.H., Bae, J.W., 2004. A look-ahead dispatching method for automated guided vehicles in automated port container terminals. Transportation Science 38, 224-234.

King, W.R., He, J., 2006. A meta-analysis of the technology acceptance model. Information \& Management 43, 740-745.

Kitzinger, J., 1994. The methodology of focus groups: the importance of interaction between research participants. Sociology of Health \& Illness 16, 103-121.

Kitzinger, J., 1995. Qualitative research: Introducing focus groups. BMJ: British Medical Journal 311, 299-302.

Larburu, M., Sanchez, J., Rodriguez, D.J., 2010. Safe road trains for environment: Human factors' aspects in dual mode transport systems. ITS World Congress, Busan, Korea .

Lee, Y., Kozar, K.A., Larsen, K.R.T., 2003. The technology acceptance model: Past, present, and future. Communication of the Association for Information Systems 12, $752-780$.

Ma, Q., Liu, L., 2004. The technology acceptance model: A meta-analysis of empirical findings. Journal of Organizational and End User Computing (JOEUC) 16, 59-72.

Madigan, R., Louw, T., Wilbrink, M., Schieben, A., Merat, N., 2017. What influences the decision to use automated public transport? using utaut to understand public acceptance of automated road transport systems. Transportation research part F: traffic psychology and behaviour 50, 55-64.

Maiti, S., Winter, S., Kulik, L., 2017. A conceptualization of vehicle platoons and platoon operations. Transportation Research Part C: Emerging Technologies 80, 1-17.

Mann, F.C., Hoffman, L.R., 1960. Automation and the worker: A study of social change in power plants.

Marangunić, N., Granić, A., 2015. Technology acceptance model: a literature review from 1986 to 2013 . Universal access in the information society 14, 81-95.

Marchau, V., Wiethoff, M., Penttinen, M., Molin, E., 2001. Stated preferences of european drivers regarding advanced driver assistance systems (adas). European Journal of Transport and Infrastructure Research 1, 291-308. 
Maréchal, S., 2016. Modelling the acquisition of travel information and its influence on travel behaviour. Ph.D. thesis. Imperial College London.

Marquié, J.C., Thon, B., Baracat, B., 1994. Age influence on attitudes of office workers faced with new computerized technologies: A questionnaire analysis. Applied ergonomics $25,130-142$.

Masoud, N., Jayakrishnan, R., 2016. Formulations for optimal shared ownership and use of autonomous or driverless vehicles, in: TRB 95th Annual Meeting Compendium of Papers.

Milakis, D., Van Arem, B., Van Wee, B., 2017. Policy and society related implications of automated driving: A review of literature and directions for future research. Journal of Intelligent Transportation Systems 21, 324-348.

Ministry of Infrastructure and Water Management, 2019. Can i use my phone while driving? URL: https://www.government.nl/topics/mobility-public-transportand-road-safety/question-and-answer/phone-while-driving.

Ministry of Transport - Singapore, 2017. Singapore to start truck platooning trials. URL: https://www .mot.gov.sg/News-Centre/News/2017/Singapore-to-start-truckplatooning-trials/.

Mittal, N., Udayakumar, P.D., Raghuram, G., Bajaj, N., 2018. The endemic issue of truck driver shortage-a comparative study between india and the united states. Research in transportation economics $71,76-84$.

Morgan, A.J., Links, S.A., 2001. Technology and the sales force: Increasing acceptance of sales force automation. Industrial Marketing Management 30, 463-472.

Morgan, D.L., 1996. Focus groups. Annual review of sociology 22, 129-152.

Müller, S., 2020. Driverless trucks in ten years-what the logistics industry needs. ATZ worldwide $122,72-72$.

Nedelkoska, L., Quintini, G., 2018. Automation, skills use and training. OECD Social, Employment and Migration Working Papers .

Neubauer, M., Schauer, O., Schildorfer, W., 2019. A scenario-based investigation of truck platooning acceptance, in: International Conference on Applied Human Factors and Ergonomics, Springer. pp. 453-461.

Neuendorf, K.A., Kumar, A., 2015. Content analysis. The international encyclopedia of political communication , 1-10. 
Nowakowski, C., Schladover, S.E., Lun, X.Y., Thompson, D., Kailas, A., 2015. Cooperative Adaptive Cruise Control (CACC) for Truck Platooning: Operational Concept Alternatives. Technical Report. California Partners for Advanced Transportation Technology UC Berkeley.

Olson, K.E., O'Brien, M.A., Rogers, W.A., Charness, N., 2011. Diffusion of technology: frequency of use for younger and older adults. Ageing international 36, 123-145.

Pai, F.Y., l Huang, K., 2011. Applying the technology acceptance model to the introduction of healthcare information systems. Technological Forecasting and Social Change 78, 650-660.

Park, I.W., Han, J., 2016. Teachers' views on the use of robots and cloud services in education for sustainable development. Cluster computing 19, 987-999.

Pink, D.H., 2011. Drive: The surprising truth about what motivates us. Penguin.

Pino, M., Boulay, M., Jouen, F., Rigaud, A.S., 2015. Are we ready for robots that care for us?" attitudes and opinions of older adults toward socially assistive robots. Frontieris in Aging Neuroscience 7, 141.

Pudāne, B., Rataj, M., Molin, E.J., Mouter, N., van Cranenburgh, S., Chorus, C.G., 2019. How will automated vehicles shape users' daily activities? insights from focus groups with commuters in the netherlands. Transportation Research Part D: Transport and Environment 71, 222-235.

Raue, M., D’Ambrosio, L.A., Ward, C., Lee, C., Jacquillat, C., Coughlin, J.F., 2019. The influence of feelings while driving regular cars on the perception and acceptance of self-driving cars. Risk analysis 39, 358-374.

Rice, S., Winter, S.R., Mehta, R., Ragbir, N.K., 2019. What factors predict the type of person who is willing to fly in an autonomous commercial airplane? Journal of Air Transport Management 75, 131-138.

Richardson, N., Doubek, F., Kuhn, K., Stumpf, A., 2017. Assessing truck drivers' and fleet managers' opinions towards highly automated driving. Advances in Human Aspects of Transportation 484, 473-484.

Robertson, R.D., Meister, S.R., Vanlaar, W.G.M., Hing, M.M., 2017. Automated vehicles and behavioural adaptation in canada. Transportation Research Part A 104, 50-57. 
Roodenbergen, K.J., Vis, I.F., 2001. A survey of literature on automated storage and retrieval systems. European journal of operational research 194, 343-362.

Schoettle, B., Sivak, M., 2014. Public opinion about self driving vehicles in China, India, Japan, the U.S, the U.K and Australia. Technical Report. University of Michigan Transportation Research Institute.

Simons, D., Clarys, P., Bourdeaudhuij, I.D., de Geus, B., Vandelanotte, C., Deforche, B., 2013. Factors influencing mode of transport in older adolescents: a qualitative study. BMC Public Health 13.

Simons, D., Clarys, P., Bourdeaudhuij, I.D., de Geus, B., Vandelanotte, C., Deforche, B., 2014. Why do young adults choose different transport modes? a focus group study. Transport Policy 36, 151-159.

Simpson, J.R., Mishra, S., Talebian, A., Golias, M.M., 2019. An estimation of the future adoption rate of autonomous trucks by freight organizations. Research in Transportation Economics 76, 100737.

Slowik, P., Sharpe, B., 2018. Automation in the long haul: Challenges and opportunities of autonomous heavy-duty trucking in the united states. The International Council on Clean Transportation .

Stephenson, F.J., Fox, R.J., 1996. Driver retention solutions: strategies for for-hire truckload (tl) employee drivers. Transportation Journal , 12-25.

Sutton, S.G., Arnold, V., 2013. Focus group methods: Using interactive and nominal groups to explore emerging technology-driven phenomena in accounting and information systems. International Journal of Accounting Information Systems 14, 81-88.

Szajna, B., 1996. Empirical evaluation of the revised technology acceptance model. Management Science 42, 85-92.

Taylor, F.W., 1911. The principles of scientific management. New York 202.

Tesla, 2019. Tesla semi. URL: https://www.tesla.com/semi.

Tesla, 2021. Autopilot. URL: https://www.tesla.com/autopilot?redirect=no.

Tsugawa, S., 2014. Results and issues of an automated truck platoon within the energy its project. Intelligent Vehicles Symposium Proceedings, 2014 IEEE , 642-647.

Walker, C.R., 1957. Towards the automatic factory. 
Walter, Z., Lopez, M.S., 2008. Physician acceptance of information technologies: Role of perceived threat to professional autonomy. Decision Support Systems 46, 206-215.

Wiethoff, M., Oei, H., Penttinen, M., Anttila, V., Marchau, V., 2002. Advanced driver assistance systems: an overview and actor position. IFAC Proceedings Volumes 35, 1-6.

Wijngaards, I., Hendriks, M., Burger, M.J., 2019. Steering towards happiness: An experience sampling study on the determinants of happiness of truck drivers. Transportation research part A: policy and practice 128, 131-148.

Wilkinson, S., Silverman, D., 2004. Focus group research. Qualitative research: Theory, method and practice, $177-199$.

Wilkowska, W., Ziefle, M., 2011. Perception of privacy and security for acceptance of e-health technologies: Exploratory analysis for diverse user groups, in: Pervasive Computing Technologies for Healthcare (PervasiveHealth), 2011 5th International Conference on, IEEE. pp. 593-600.

World Maritime University, 2019. Transport 2040: Truck platooning: The Australian case Technology and transformation.

Yang, J., Coughlin, J.F., 2014. In-vehicle technology for self-driving cars: Advantages and challenges for aging drivers. International Journal of Automotive Technology 15, 333-340.

Yang, S., Shladover, S.E., Lu, X.Y., Spring, J., Nelson, D., Ramezani, H., 2018. A first investigation of truck drivers' on-the-road experience using cooperative adaptive cruise control. Transportation Research Record: Journal of the Transportation Research Board .

Yassuda, M.S., Wilson, J.J., van Mering, O., 1997. Driving cessation: The perspective of senior drivers. Educational Gerontology: An international quarterly 23, 525-538.

Zaunbrecher, B.S., Beul-Leusmann, S., Ziefle, M., 2014. Laypeople's perspectives on electromobility: A focus group study. International Internet of Things summit 2014, $144-149$.

Ziefle, M., Valdez, A.C., 2017. Domestic robots for homecare: A technology acceptance perspective. Human Aspects of IT for the Aged Population. Aging, Design and User Experience, 57-74. 
A Participant details 


\begin{tabular}{|c|c|c|c|}
\hline Name & Age & Goods & Trip type(s) \\
\hline James & & Container & National and international \\
\hline William & 32 & Container & International \\
\hline John & & Container & International \\
\hline Andrew & 45 & Keeper & International \\
\hline Adam & & Garbage & National and international \\
\hline George & & Container & National and international \\
\hline $\operatorname{Max}$ & 53 & Container & National \\
\hline Simon & 50 & Container & National \\
\hline Harry & 62 & Container & National \\
\hline Yohan & 25 & Container & National and international \\
\hline Ashley & 53 & Container & National \\
\hline Daan & 57 & Container & National and international \\
\hline Jaap & 62 & Container & National \\
\hline Jay & 45 & Container and cars & National \\
\hline Michael & 55 & Container & National \\
\hline Gabriel & 31 & Container and cooler & National \\
\hline Rudy & 35 & Ferry & National \\
\hline Martin & 63 & Ferry & National \\
\hline Robert & 32 & Liquid waste & National \\
\hline Jan & 39 & Ferry & National \\
\hline Grant & 27 & Miscellaneous & International \\
\hline Shawn & 54 & Produce, paper, parts & International \\
\hline Roger & 57 & Pallets & International \\
\hline Paul & & Container & National \\
\hline Tim & 47 & Bulk & National and international \\
\hline
\end{tabular}

Table 2: Details of participants (names have been changed for privacy, empty cells indicate that drivers chose to withhold this information) 